\title{
CARDIAC ARRESTS IN THE OPERATING ROOM - PART I (1965-1974)
}

\section{MinUCK}

THE wORLD MEDiCal LITERATURE is filled with articles and reports of cardiac arrests in hospitalized patients, but aside from anecdotal accounts of operating room cardiac arrests associated with a particular drug or procedure, few detailed analyses of such arrests have been published. Moreover, very little information has been made available in recent years about the influence of the method of cardiac compression used by the attending physicians on the survival rate of patients whose hearts arrest in the operating room.

The objective of this article is to present a study and analysis of the incidence of cardiac arrests in our surgical suites, review the methods used for cardiac compression in the management of the arrest, relate the procedures used to survival rate achieved, and finally, to suggest how the number of ultimate survivors might be increased above the current reported rate. Neither aetiological and precipitating factors, or ancillary chemotherapy and electrotherapy are included in this presentation.

Cardiac arrest is defined as a sudden and unexpected arrest of the circulation. Clinical evidence for this catastrophe includes the sudden disappearance of pulse and blood pressure, and sudden absence of breathing in those patients to whom muscle relaxants have not been administered. Moribund patients suffering from severe cardiovascular collapse associated with massive trauma, massive haemorrhage, cardiogenic or septic shock, who go on to die during or immediately after operation are not considered to meet the criteria laid down for the diagnosis of cardiac arrest and have been excluded from this study.

\section{Materials and Methods}

This paper is based on the cases of cardiac arrest which took place in the operating room or the post-anaesthesia recovery room of the St. Boniface General Hospital during a ten year period from January 1, 1965 to December 31, 1974.

The St. Boniface General Hospital is a 625 bed acute general hospital, affiliated with the University of Manitoba Medical Faculty. All types of surgery are done including open-heart and major neuro-surgical procedures. It has been a long standing custom for the members of the Department of Anaesthesia to regularly review the records and retain a brief description of all deaths occurring during or within seven days of operation and anaesthesia. Similarly, all cardiac arrests which take place in the operating suite are reviewed. The review includes a judgement decision as to whether the arrest and/or death was related to the surgery, anaes-

${ }^{\circ}$ Head, Department of Anaesthesia, St. Boniface General Hospital, St. Boniface, Manitoba. Professor of Anaesthesia, University of Manitoba. 
TABLE I

Cardiac Arrests in the Operating Room (1965-1974)

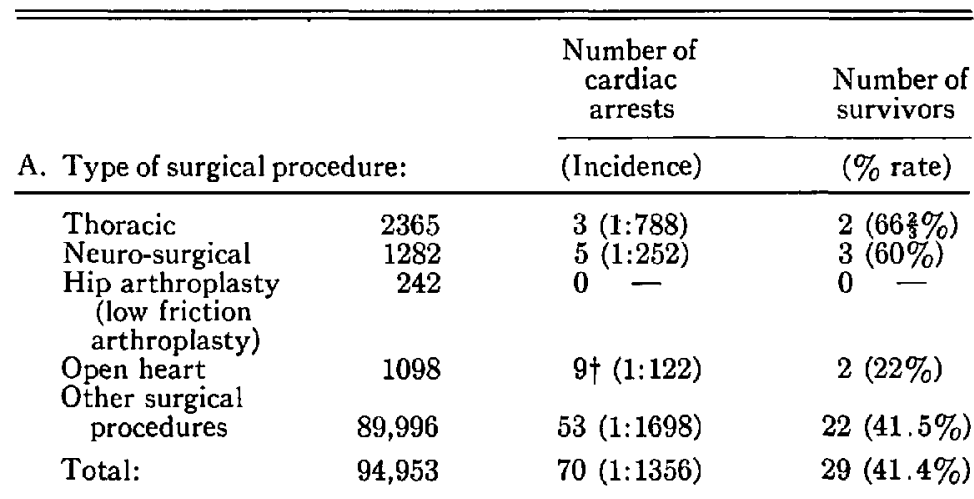

Cardiac arrests related to anaesthesia*

B. Anaesthetic techniques:

\begin{tabular}{lrlr} 
General & 88,311 & $31(1: 2,849)$ & $18(58 \%)$ \\
$\begin{array}{l}\text { Regional alone } \\
\quad \text { or with general }\end{array}$ & 6,622 & $11(1: 602)$ & $6(54.5 \%)$ \\
Total & 94,953 & $42(1: 2260)$ & $24(57.1 \%)$ \\
\hline
\end{tabular}

*Only those cases where it was felt that anaesthesia contributed significantly to the cardiac arrest are included in this section.

tBecause of the special circumstances that normally surround cardiac procedures this does not accurately describe the number of cardiac arrests in this category of patient.

thesia, patient status, or to combinations of these factors. The records of this concurrent audit form the basis of this presentation.

\section{RESULTS}

During the period under review, 94,953 surgical operations were done. Table I contains a list of the types of surgical procedures done and the types of anaesthesia used. The incidence of cardiac arrest and the survival rate in each category is also described. General anaesthesia, including anaesthetic "stand-by", was used in 88,331 instances (93.1 per cent), and regional analgesia, often combined with general anaesthesia, was used in 6,622 procedures ( 6.9 per cent). Seventy cardiac arrests occurred during this period for an overall incidence of 1:1,356. Forty-two patients (60 per cent) were resuscitated, but only 29 patients, or 41.4 per cent of those who arrested were discharged from the hospital alive and well and considered to be permanent survivors. The incidence and outcome of anaesthesiarelated cardiac arrests and of the total groups are compared in Table II. It can be seen that the percentage of permanent survivors is higher in the anaesthesia-related category than in the total group. These cases of cardiac arrest will be presented in detail in another article.

Table III relates the survival rate to the methods utilized for cardiac compression during the resuscitation effort. Of the 50 patients in whom closed chest compression was used, 18 patients did not respond to treatment, and of those that did, nine 
MINUCK: CARDIAC ARRESTS IN THE OPERATING ROOM

TABLE II

Cardiac Arrests in the Operating Room-Part I JANUARY 1965-DECEMBER 1974

\begin{tabular}{lcc}
\hline Total number of anaesthetics: & 94,953 & \\
& Total & $\begin{array}{c}\text { Anaesthesia* } \\
\text { related }\end{array}$ \\
\hline Cardiac arrests & 70 & 42 \\
Cardiac arrests & $1: 1,356$ & $1: 2,260$ \\
$\quad$ incidence) & 28 & 8 \\
Immediate failures & 13 & 10 \\
Temporary survivors & $29(41.4 \%)$ & $24(57.1 \%)$ \\
Permanent survivors & $1: 2,316$ & $1: 5,593$ \\
Mortality rate & & \\
\hline
\end{tabular}

*Only those cases where it was felt that anaesthesia contributed significantly to the cardiac arrests are included in this section.

TABLE III

Cardiac Arrests in the Operating Room-Part I JANUARY 1965-DECEMBER 1974

\begin{tabular}{ccccc}
\hline \hline & Closed & Open & $\begin{array}{c}\text { Closed first } \\
\text { followed by } \\
\text { open }\end{array}$ & Total \\
\hline $\begin{array}{c}\text { Immediate } \\
\text { deaths }\end{array}$ & 18 & 7 & 3 & 28 \\
$\begin{array}{c}\text { Temporary } \\
\text { survivors }\end{array}$ & 9 & 2 & 2 & 13 \\
$\begin{array}{c}\text { Permanent } \\
\text { survivors }\end{array}$ & 23 & 5 & 1 & 29 \\
Total & 50 & 14 & 6 & 70 \\
\hline
\end{tabular}

In this table the cases of cardiac arrest are grouped according to the procedure used for cardiac compression.

died at a later date. Only 23 , or 46 per cent, of the patients in this group became permanent survivors. Fourteen patients were treated with immediate direct cardiac compression (in most instances the chest was already open when the cardiac arrest occurred). Seven did not respond, but only two of those who responded immediately died later for a permanent survival rate at 35.7 per cent (five patients). In six patients, closed cardiac compression was followed at a variable interval by direct cardiac compression. It is of some significance that only one patient in this group survived to leave the hospital.

\section{Discussion}

Sudden and unexpected death during anaesthesia has a history nearly as long as anaesthesia itself. The first reported instance of cardiac arrest occurred on January 28, 1848 during a chloroform anaesthetic. The young patient whose heart arrested was not resuscitated. ${ }^{1}$ Henry M. Lyman reported that the first death during nitrous oxide anaesthesia took place in $1864 .^{2} \mathrm{He}$ further recorded that the first death during the inhalation of ether occurred in $1861 .^{3}$ Successful resuscitation of a patient whose heart had stopped during anaesthesia took place a few years 
later. John Stetson reported that a patient was successfully resuscitated following a cardiac arrest during anaesthesia on June 19, 1867 with the use of a "tracheotomy and the application of galvanism to the cardiac region". ${ }^{4}$ According to James $\mathrm{R}$. Jude, et al., the first successful cardiac resuscitation with closed chest cardiac compression took place in 1891 , and he further reported that direct cardiac compression was first used with success in $1901 .^{5}$ This latter method was virtually abandoned after 1960 when Kouwenhoven, Jude and Knickerbocker re-introduced closed chest compression, ${ }^{6}$ and Kouwenhoven and others described their success with external electrical ventricular defibrillation. ${ }^{7}$

A voluminous literature attests to the fact that the introduction of external cardiac compression and external ventricular defibrillation has brought about a dramatic improvement in survival rates in those patients whose hearts arrested outside the operating room. The increase has been from nearly 0 to as high as 15 per cent in some reports, and still better when the cardiac arrest occurred in patients who were being cared for in coronary care units and other specialized intensive care areas. ${ }^{8-11} \AA$ study of the English language literature has shown that such amelioration of death rates has not occurred in patients whose hearts arrest in the operating room in spite of the fact that surgical patients usually have less cardiac and pulmonary impairment than those who develop sudden and unexpected circulatory arrest in general care wards.

Briggs, Sheldon and Beecher, in a review of operating room cardiac arrests, between 1924 and 1954, indicated a recovery rate of 50 per cent during the last five years of their review. ${ }^{12}$ Their recommended method of treatment was "immediate diagnosis, prompt thoracotomy and manual systole." They also pointed out that artificial respiration and the judicious use of drugs were essential. Engell, et al., in 1959, presented a detailed review of the management of thirty cases of cardiac arrest during anaesthesia and surgery. ${ }^{13}$ Their preferred method of treatment included thoracotomy for cardiac compression and their efforts resulted in a 60 per cent permanent recovery rate, although one patient was discharged from hospital with a severe neurological deficit, and three others with "slight" cerebral damage.

In 1970, Jude, et al., described a forty-three per cent survival when external cardiac compression was utilized for cardiac resuscitation in the operating room. ${ }^{5}$ McLure, et al., in 1972, experienced a 50 per cent survival rate in their report on twenty-four patients whose hearts had arrested in the surgical suite. ${ }^{14}$ Two unsuccessful attempts at direct or open cardiac compression were included in their report. In a more recent report, G.G. Harrison presented a permanent survival rate of only 19 per cent ( 17 out of 89 cases) of operating room cardiac arrests, but his series contained thirty-three instances of massive haemorrhage, and one of massive pulmonary embolus. ${ }^{15}$ Even when such cases are deleted from the series, the success rate rises to only 33 per cent. Admittedly some of our patients failed to respond to treatment because of factors incompatible with continuing life, such as massive pulmonary emboli (see Table IV), yet the survival rate of 41.4 per cent is disappointingly low; and even though our results compare favourably with other published reports it would seem reasonable to look for techniques that may attain higher survival rates following cardiac arrest in the operating room. 
TABLE IV

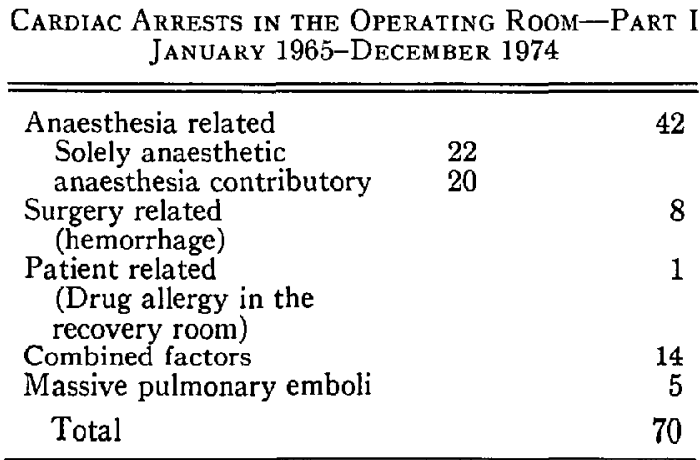

Pierce expressed his disenchantment with external cardiac compression in 1966 when he reported 22 consecutive failures following the use of this technique. ${ }^{16}$ In his review Pierce also refers to the 50 per cent recovery rate reported by Briggs, et al., ${ }^{12}$ almost two decades before. Twenty-three patients in our series did survive with the use of external cardiac compression, but only one (see Case 3) of six patients survived when thoracotomy with direct cardiac compression was utilized after a variable trial period of closed or external cardiac compression. On the other hand, James C. Drye, in 1970, reported six consecutive successes in the management of cardiac arrest during surgical procedures. His method consisted of immediate thoracotomy and direct cardiac compression. ${ }^{17}$

Weale and Rothwell-Jackson demonstrated long ago that significantly higher perfusion pressures are attainable in fibrillating dogs with internal cardiac compression than with external cardiac compression. ${ }^{20}$ Del Guerico, et al., showed that the cardiac output obtained during closed chest compression was only half of the cardiac output obtained during open cardiac compression in man. ${ }^{21}$ Cohn and Del Guerico studied this problem further on clinical subjects by means of a mobile catheterization laboratory. Short-term resuscitation was achieved in five of six patients using internal or direct cardiac compression, but in only one out of six using external cardiac compression. ${ }^{22}$ Our relatively poor results, as well as those reported by others, may be explained by the severely reduced cardiac output produced by external cardiac compression combined with the delay in the utilization of the relatively more efficient technique of direct cardiac compression.

\section{Case Reports}

\section{Male (71)}

Procedure: Transurethral Resection of the Prostate. Anaesthesia was induced with thiopentone and following an intubating dose of succinylcholine, a tracheal tube was inserted. Shortly after "intubation" the patient was cyanosed, the blood pressure soon disappeared, and his pulse slowed markedly. Oxygen (100 per cent) was administered and closed chest compression was instituted. As there was no response after an estimated 8 to 10 minutes, a left thoracotomy was performed and direct cardiac compression was begun. The heart began to beat spontaneously 
very shortly thereafter and the pulse and blood pressure and skin color returned to normal. The patient never regained consciousness, however, and he died seven days later. Autopsy demonstrated little beyond severe anoxic brain damage.

Comment: When the chest was opened the lung quickly collapsed. That the tracheal tube had been placed into the oesophagus had not been revealed before, in spite of utilizing all the usual methods for checking the placement of the tube into the trachea. These methods included auscultation of both sides of the chest and assessment of the movement of the chest wall on intermittent compression of the breathing bag; nor was there any escape of oxygen from the oesophagus. Had the thoracotomy been done at, or before, the two-minute mark, prior to the development of irreversible brain damage, this patient might well have survived.

\section{Female (33)}

Procedure: Relief of bowel obstruction due to volvulus of caecum. Following an uneventful hemicolectomy under general anaesthesia, the patient was taken to the post-anaesthesia recovery room. On admission to the unit the nurse noted that the patient was cyanosed and within minutes the blood pressure and pulse had disappeared. She was intubated immediately, ventilated with 100 per cent oxygen and closed chest compression was begun. This was continued for approximately 20 minutes. Finally, since there was no response to treatment, a left thoracotomy was done and direct cardiac compression started. The patient failed to respond and resuscitation efforts were abandoned. Autopsy did not reveal an obvious cause of death.

Comment: A detailed review of all aspects of this case revealed that the cause of arrest was likely due to inadequate ventilation in an over-curarized, obese, but otherwise healthy female. It is speculated that earlier use of direct thoracotomy and the production of a higher cardiac output might have resulted in the survival of this patient.

\section{Male (14)}

Procedure: Open reduction of the hip in a fairly obese, but otherwise healthy young boy. The operation was proceeding under general anaesthesia with nitrous oxide, oxygen and halothane. Approximately 90 minutes following intubation, and while the patient was breathing spontaneously, the anaesthetist noted a sudden absence of pulse and blood pressure and breathing ceased. As there was no immediate response to controlled ventilation with 100 per cent oxygen and closed chest compression, a left thoracotomy was done and direct cardiac compression was started within two minutes. There was an immediate resumption of cardiac activity and the patient recovered without sequelae.

Comment: It is felt that the favourable response resulted from an early recognition that the closed chest compression was not producing an acceptable cardiac output followed by the decision to use direct cardiac compression immediately.

The preceding case reports are presented in support of our impression that, only by early use of the more effective technique of direct cardiac compression can higher survival rates be achieved following cardiac arrest in the operating room. Aside from the usual methods it is suggested that if there is no resumption of 
TABLE V

MANAGEMENT OF CARDIAC ARREST IN THE OPERATING ROOM

1. Start ventilation with $100 \%$ oxygen (note the time).

2. Thump the chest.

3. Commence external cardiac compression.

4. Attach electrocardiograph or cardioscope.

A. STANDSTILL: (Asystole) No recognizable electrical activity.

Epinephrine $-1 \mathrm{ml}$ of $1 / 1000$ diluted to $10 \mathrm{ml}$ with saline and 5-10 $\mathrm{ml}$ injected directly into the I.V. tubing or into the endotracheal tube.

B. venthicular fibrillation: Completely disorganized rhythm. External Electrical Defibrillation - 150 Joules and increase.

5. If there is no response within 1 to 2 minutes, or if it is impossible to identify the type of arrest:

(a) Incision is made at the 4th or 5th interspace on the left side and carried through the chest wall. Start the incision at least two inches away from the sternal edge.

(b) A hand is introduced to palpate the heart. Opening the pericardium is not essential.

(c) Cardiac compression is started immediately. Rate of compression is $60-80$ per minute. The radial pulse can be felt if the compression is adequate.

(d) Cardiac Standstill: The heart feels like a "wet blanket." Ventricular Fibrillation: The heart feels like a "bag of worms."

(e) Internal Defibrillation - Only after blood has become red with cardiac compression. Electrodes are placed on both sides of the ventricles. Gradually increase the strength from 25 joules.

6. Rapid replacement of blood volume.

7. Other drugs as indicated.

cardiac function within two minutes, left thoracotomy should be performed and direct cardiac compression commenced. The recommended procedure for the management of cardiac arrest is tabulated in Table $\mathrm{V}$.

\section{SUMMARY}

A ten-year review of the incidence of cardiac arrest in the operating suite at the St. Boniface General Hospital has been presented. Seventy cardiac arrests occurred during this period, and 29 were permanently resuscitated for a survival rate of 41.4 per cent. This rate compares favourably with the published experience of other centres. It does not, however, reflect an improvement over the survival rates published prior to 1960 , a point in time when direct cardiac compression for the management of these cases was virtually abandoned in favor of external cardiac compression. To improve surviva!, a plea is made for return to early use of thoracotomy and direct cardiac compression in the treatment of cardiac arrest in the 
operating room. To accomplish this end all surgeons and anaesthetists should become familiar not only with the techniques required for these procedures, but also with the prevention and management of any associated complications.

\section{RÉSUMÉ}

Ce travail analyse les arrêts cardio-respiratoires survenus en salle d'opération durant les dix dernières années (1965-1974) à l'Hôpital Générale de St-Boniface.

On dénombre 70 arrêts durant cette période dont 29 été réanimés avec un succès permanent établissant un taux de survie de 41.4 pour cent qui se compare avantageusement avec les taux publiés par d'autres auteurs.

Cependant, ce taux ne montre pas d'amélioration sur celui des années d'avant 1960, date où on a presque complètement remplacé le massage direct interne par la compression sternale externe.

Dans l'espoir d'améliorer le taux de survie, ce travail veut être un plaidoyer en faveur d'un retour aux pratiques d'avant 1960 devant un arrêt cardiaque: soit le recours précoce à la thoracotomie et au massage cardiaque direct interne.

Dans cette optique, chirurgiens et anesthésiologistes se doivent de bien maîtriser ces techniques et aussi d'en connaître les complications afin de savoir les prévenir et/ou les traiter.

\section{REFERENCES}

1. First incidence of cardiac arrest during chloroform anaesthesia. Amer. J. Med. Science, 558 (1848).

2. Lyman, H.M. Artificial anaesthesia and anaesthetics. William Wood \& Co., New York, 323 (1881).

3. Ibid: p. 289.

4. Stetson, J.B. Resuscitation under anaesthesia - some interesting early reports. Anesth. 20:62 (1959).

5. Jude, J.R., et al. Cardiac resuscitation in the operating room: current status. Annals of Surg. 171: 948-955 (1970).

6. Kouwenhoven, W.B., Jude, J.R., \& Knickerbocker, G.G. Closed chest cardiac massage. J.A.M.A. 173: 1064 (1960).

7. Kouwenhoven, W.B., et al. Closed chest defibrillation of the heart. Surg. 42: 550 (1957).

8. Collins, V.J. Iatrogenic cardiac arrest. New York State J. Med., 3107-3109 (1961).

9. Brown, C.S. \& ScotT, A.A. Cardiopulmonary resuscitation. C.A.S.J., 17: 565-572 (1970).

10. Minuck, M. \& Perkins, R. Long-term study of patients successfully resuscitated following cardiac arrest. C.A.S.J., 100: 1126-1128 (1969).

11. Johnson, A.L., et al. Results in cardiac resuscitation in 552 patients. Amer. J. Cardiol. 20: $831(1967)$.

12. Briccs, B.D., Sheldon, D.B., \& Beechen, H.K. Cardiac arrest. J.A.M.A. 106: 1439-1444 (1956).

13. Engeli, H.C., Price, J., \& Secher, O. Cardiac arrest during anaesthesia and surgery. Acta Anaesthesiologica Scand. Suppl. I (1959).

14. Mclune, J.N., Skardasis, G.M., \& Brown, J.M. Cardiac arrest in the operating area. The American Surgeon 38: 241-246 (1972).

15. Harrison, G.G. Anaesthetic-associate mortality. S.A. Mediese Tydskrif, 550-554 (1974).

16. Pierce, J.A. Cardiac arrests and deaths associated with anaesthesia. Anesthesia and Analgesia 45: 407-413 (1966).

17. DRYE, J.C. In discussion of Jude, et al. ( ref. 5 ) p. 955.

18. MEMERY, H.N. Anesthesia mortality in private practice. J.A.M.A. 194: 1185-1188 (1965).

19. ВовA, A. \& LANDmesser, C.M. Total cardiorespiratory collapse (cardiac arrest) contribu- 
tory and causative errors of omission and commission for which the anesthesiologist must assume responsibility. New York State J. Med., Part I, 2928-2936 (1961).

20. Weale, F.E. \& Rothwell-Jackson, R.C. The efficiency of cardiac massage. The Lancet, 990-992 (1962).

21. DeL Guerico, L.R.M., et al. Comparison of blood flow during external and internal cardiac massage in man. Circulation (Suppl. I) 32: 171 (1965).

22. Conn, J.D. \& Dec GueRico, L.R.M. Cardiorespiratory analysis of cardiac arrest and resuscitation. S.G. \& O., 123: 1066-1070 (1966). 